\title{
Sağlık Hizmetleri Meslek Yüksekokulu Öğrencilerinin Sosyal Medya Kullanım Özellikleri ve Tutumlarının İncelenmesi
}

Prof. Dr. Mukadder Mollaoğlu'

Öğr. Gör. Fatma Hastaoğlu ${ }^{2}$

Arş. Gör. Esra Başer ${ }^{3 *}$

Öğr. Gör. Songül Mollaoğlu ${ }^{4}$

Geliș tarihi: 18.02.2019

Kabul tarihi: 10.03.2019

\section{Atıf bilgisi:}

Uluslararası Bilimsel Araștırmalar Dergisi (IBAD)

Cilt: $4 \quad$ Sayı: 2

Sayfa: 157-166 Yıl: 2019

Dönem: Yaz

This article was checked by iThenticate. Similarity Index 22\%

1 Sivas Cumhuriyet Üniversitesi, Türkiye, mukaddermollaoglu@hotmail.com,

ORCID ID: 0000-0002-9264-3059

2 Sivas Cumhuriyet Üniversitesi, Türkiye, fhastaoglu@,cumhurivet.edu.tr

ORCID ID: 0000-0001-8929-2860

${ }^{3}$ Sivas Cumhuriyet Üniversitesi, Türkive, esrabaser568@hotmail.com, ORCID ID: 0000-0003-3618-3622

${ }^{4}$ Sivas Cumhuriyet Üniversitesi, Türkiye, songul.mollaoglu@,cumhuriyet.edu.tr, ORCID ID: 0000-0002-3519-8702

* Sorumlu yazar

\begin{abstract}
ÖZ
Hız, erişim ve kullanım kolaylığının vermiş olduğu kolaylıklar nedeniyle sosyal medyanın eğitim açısından iletişim, sorgulama, araştırma, aktif katılım, işbirliği sağlayıcı ortam, doküman, bilgi ve deneyimlerin paylaşımı gibi çok önemli olanaklar sağladığı bilinmektedir. $\mathrm{Bu}$ bağlamada sosyal medya, etkili kullanıldığında eğitimde avantajlı bir konuma sahiptir. Bu nedenle öğrencilerin sosyal medyayı nasıl kullandıkları ve sosyal medyaya yönelik tutumlarını belirlemek önem kazanmaktadır. Betimsel tasarımın kullanıldığı bu çalışmada veriler, çalışmaya katılmaya istekli 342 katılımcıdan yüz yüze görüşme tekniğiyle toplanmıştır. Araştırmanın verileri literatürden yararlanarak oluşturulan ve toplam iki bölümden oluşan soru formu ve Sosyal Medya Tutum Ölçeği ile elde edilmiștir. Çalıșma sonunda, öğrencilerin zamanlarının büyük bir kısmını sosyal medyada geçirdikleri ve sosyal medya kullanımının gençlerin günlük yaşam aktivitelerinin önemli bir bölümü haline geldiği belirlenmiştir. Ayrıca öğrencilerin sosyal medyayı en çok sosyal paylaşım amaçlı aktiviteler (fotoğrafvideo paylaşımı, sohbet etme) için kullandıkları, çok az öğrencinin eğitimlerine katkı amacıyla bu ağlardan yararlandıkları ve sosyal medyaya karşı olumlu tutum içinde oldukları ortaya çıkmıştır. Çalışmada öğrencilerin zamanlarının büyük bir kısmını geçirdikleri sosyal medyayı eğitimleri için etkili, yeterli ve bilinçli bir şekilde kullanamadıkları sonucuna ulaşılmıştır.
\end{abstract}

Anahtar Kelimeler: İnternet,Sosyal Medya, Sosyal Ağlar, Tutum, Öğrenci 
Investigation of Social Media Usage Features and Attitudes of Vocational School of Health Services Students

\author{
Prof. Dr. Mukadder Mollaoğlu \\ Lecturer Fatma Hastaoğlü ${ }^{2}$ \\ Res. Asst. Esra Başer ${ }^{*}$ \\ Lecturer Songül Mollaoğlu ${ }^{4}$
}

First received: 18.02.2019

Accepted: 10.03.2019

\title{
Citation:
}

Journal of the International

Scientific Research (IBAD)

Volume: 4 Issue: 2

Pages: 157-166 Year: 2019

Session: Summer

This article was checked by iThenticate. Similarity Index 22\%

\footnotetext{
1 Sivas Cumhuriyet University, Turkey, mukaddermollaoglu@hotmail.com,

ORCID ID: 0000-0002-9264-3059

2 Sivas Cumhuriyet University, Turkey, fhastaoglu@cumhurivet.edu.tr

ORCID ID: 0000-0001-8929-2860

3 Sivas Cumhuriyet University, Turkey, esrabaser568@hotmail.com, ORCID ID: 0000-0003-3618-3622

${ }^{4}$ Sivas Cumhuriyet University, Turkey, songul.mollaoglu@,cumhuriyet.edu.tr, ORCID ID: 0000-0002-3519-8702
}

* Corresponding author

\begin{abstract}
It is known that social media provides important opportunities such as communication, questioning, research, active participation, sharing environment, document, information and experiences in terms of education, due to speed, access and ease of use. In this context, social media has an advantageous position in education when used effectively. Therefore, it is important to determine how students use social media and their attitudes towards social media. This research was conducted to examine the social media usage characteristics and attitudes of the students of the Vocational School of Health Services. In this study using descriptive design, the data were collected from 342 participants who were willing to participate in the study by face to face interview technique. The data of the study were obtained by using a questionnaire consisting of two parts and using the Attitude Scale towards Social Media. At the end of the study, it was determined that the students spent most of their time on social media networks and the use of social media became an important part of the daily life activities of young people. In addition, it was found out that the students mostly used social media for social sharing activities (photo-video sharing, chatting), few students benefited from these networks to contribute to their education and they had a positive attitude towards social media. In the study, it was concluded that the students could not use social media which they spent most of their time in an effective, sufficient and conscious way for their education.
\end{abstract}

Keywords: Internet, Social Media, Social Networks, Attitude, Student 


\section{Gİİş}

Günümüzde neredeyse her alanda ve ortamda her yaştaki birey için sosyal medya, yaşamın vazgeçilmez bir parçası niteliğindedir. İnternet kullanımının önemli bir kısmını oluşturan sosyal medya özellikle gençler arasında yaygın kullanılmaktadır. Hız, erişım ve kullanım kolaylığının vermiş olduğu kolaylıklar nedeniyle sosyal medyanın eğitim açısından iletişim, sorgulama, araştırma, aktif katılım, iş birliği sağlayıcı ortam, doküman paylaşımı, bilgi ve deneyimlerin paylaşımı gibi çok önemli olanakları barındırdığı bilinmektedir. Bu bağlamda sosyal medya eğitimde avantajlı bir konuma sahiptir. Bu nedenle öğrencilerin sosyal medyayı nasıl kullandıkları ve sosyal medyaya yönelik tutumlarını belirlemek önem kazanmaktadır.

\section{Sosyal Medya Kavramı}

Sosyal medya, internet kullanıcılarının birbirleri ile etkileşim içinde oldukları, paylaşımlar yaptıkları ve görüş alışverişinde bulundukları sosyal ağ ortamları olarak tanımlanabilir (Kirtiş ve Karahan, 2011, s.262). Diğer bir tanıma göre sosyal ağlar, kullanıcıların kişisel bilgilerini paylaşma, özel veya çevrimiçi mesajlar gönderme, fotoğraf ve video paylaşımı gibi yollarla diğer kullanıcılarla iletişim kurmalarını sağlayan internet toplulukları olarak tanımlanmıştır (Pempek, Yermolayeva ve Calvert 2008, s.228).

Hızlı ilerleyen internet teknolojisiyle birlikte sosyal medya günümüzde en önemli iletişim araçlarından biri haline gelmiştir. İnternetin kullanımı yaygınlaşması sonucu sosyal medya kullanıcıları da önemli oranda artmaktadır. Günlük yaşamın vazgeçilmez iletişim araçlarından biri olan sosyal medya araçları, birçok kullanıcı tarafindan sıklıkla tercih edilmektedir (Hazar, 2011, s.153). Sosyal medya sürekli olarak güncellenmekte, çoklu kullanım imkanı sağlayan ve paylaşıma açık olan platformları sayesinde popülaritesini her geçen gün daha fazla arttırmaktadır. Sosyal medya uygulamaları sadece bireyler arasında iletişimi sağlamakla sınırlı olmamakta aynı zamanda kullanıcıların bilgi taleplerini karşılamakta ve istedikleri konuda arama yapmalarını da olanaklı kılmaktadır (Akar, 2010; Vural ve Bat, 2010, S.3350; Fuvhs, 2017, s.30). Sosyal medya aracı olan sosyal ağ siteleri Facebook, Twitter, Instagram, MySpace vb. şeklinde sürekli gelişmekte ve yenileri eklenmektedir (Kim, Jeong ve Lee, 2010, s.218-219). "We Are Social" tarafindan hazırlanan "Digital in 2018 in Western Asia" isimli 2018 yılı raporunda Türkiye'de 51 milyon sosyal medya kullanıcısı olduğu ve ilk sırada Youtube, sonrasında sirayla Facebook ve Instagram gelmektedir (We are social, 2018).

\section{Sosyal Medya Kullanımına İlişkin Görüşler}

Sosyal ağların kullanımına ilişkin farklı görüşler bulunmaktadır. Sosyal ağlar kullanıcıları sosyalleştirdiğini savunanlar olduğu gibi tam tersini savunanlar da bulunmaktadır. Bir görüşe göre sosyal ağları kullanım amaçlarının farklı olması ile birlikte genelde eski arkadaşları bulma, yeni bir kimlik oluşturma, eğlenmek gibi amaçlar ile kullandıklarını. Bu nedenler ile bireylerin sosyalleşmediğini, mevcut olan ilişkilerini geliştirdiğini savunmaktadırlar (Hazar, 2011, s.153). Diğer görüşe göre ise kullanıcıların yeni arkadaşlar edinmesi, fotoğraf, metin gibi içeriklerin paylaşılması, bireyleri sosyalleştirmektedir (Kahraman, 2010, s.6). Günlük hayatta yalnızlaşan insanlar için sosyal medya farklı kişilerle tanışma ve etkileşim kurmalarını sağlamaktadır (Kuyucu, 2013, s.117).

Sosyal medya araçları geleneksel medya araçlarına göre birçok farklılığa sahiptir. Bu farklılıklardan en önemlileri daha az maliyetli ve erişim imkanlarının herkese açık olmasıdır. Sosyal medya araçları üzerinden kullanıcılar istedikleri bilgileri paylaşabilmekte ve istedikleri bilgiye rahatlıkla ulaşabilmektedir. Sosyal medyanın geleneksel medyadan en önemli farklılıklarından biri de sosyal medya içeriklerinin çoğunluğunun kullanıcılar tarafından oluşturulmasıdır. Bu durum sosyal medya içeriklerinin geleneksel medyaya göre oldukça yoğun olmasından kaynaklanmaktadır (Kaplan ve Haenlein, 2010, s.60; Patel, 2017, s.14). Ayrıca sosyal medya araçları her kullanıcı için kişisel sayfa imkanı sağlamakta ve kullanıcılar profil bilgilerini bu sayfalar üzerinde paylaşabilmektedir. Sosyal medya araçları ile kullanıcılar iletişim kurmanın yanı sıra arkadaş edinebilmekte, gruplara 
katılabilmekte, fotoğraf, video ve metin gibi içerik paylaşımında bulunabilmektedirler (Lin vd., 2016, s.329; Pangrazio ve Selwyn, 2018, s.1).

Geleneksel medya araçlarında aktarılmak istenen bilgi, hedef kitlelere aktarılmakta ve bireysel özellikler dikkate alınmamaktadır. Sosyal medya araçları ise merkezi bir paylaşım ortamı yaratmakla beraber bireysel özellikleri dikkate almaktadır. Sosyal medya araçlarında geleneksel medya araçlarında olduğu gibi tek yönlü bir iletişim söz konusu değildir ve interaktif bir erişim imkanı sağlanmaktadır. Kullanıcılar istedikleri bilgiyi paylaşabilmekte ve paylaştıkları bilgi ile ilgili geri bildirim alabilmektedir (Yağmurlu, 2011, s.6; Barutçu ve Tomaş, 2013, s.18).

Ayrıca sosyal medya araçları kullanıcıları bireyselleştirmekte aynı zamanda yeni bir toplumsal yapı oluşturmaktadır. Kullanıcılar sosyal medya araçları üzerinden kurdukları ilişkilerini gerçek yaşamlarında sürdürebilme arzusu içinde olmaktadır. Bireyler kişisel ihtiyaçlarını ve yaşam tarzlarını dijital ortamlarda başkalarıyla paylaşmakta ve elde ettikleri deneyimlerle birbirleriyle bağlantı kurmaktadır. Bireyler sosyal medya araçları üzerinden başkalarıyla kurdukları bağlantılar ile grup kimliklerini yaratmaktadır (Solmaz vd., 2013, s.24; Öztürk ve Talas, 2015, s.109; Çağlar, 2014, s.488).

Günümüzde toplumsal olayların birçoğunun yaşanmasında sosyal medya araçlarının etkin olarak kullanıldığı görülmektedir. Sosyal medyanın kullanıcılar için özgür bir ortam olması ve mekandan bağımsız olması bireylerin istedikleri şekilde ortamı etkin olarak kullanmalarını sağlamaktadır (Onat, 2010, s.49). Özellikle gençler tarafından sıklıkla kullanılan sosyal paylaşım siteleri sayesinde bilgi paylaşımı yaygın şekilde yapılabilmektedir. Gençlerin sosyal medya kullanım amaçlarının belirlenmesi, gelecekte toplumsal davranışlar hakkında bir yargıya ulaşılması adına önemlidir (Çildan vd., 2012, s.2; Eren ve Aydın, 2014, s.198).

\section{3. Öğrencilerin Sosyal Medya Kullanım Özellikleri}

Üniversite öğrencileri yaşları ve bulundukları konum gereği günlük hayatta sosyal medya araçlarını sık kullanmaktadırlar. Eğitim aldıkları süreçte bilgi paylaşımı, yeni arkadaşlar edinme, yeni kimlik ve kişilik kazanma, araştırma yapma ve eğlenme gibi birçok nedene bağlı olarak sosyal medyayı kullanmaktadırlar (Karaca, 2007: 11-16). Son yıllarda literatürde gençlerin sosyal medya kullanım alışkanlıklarını tespit etmek amacıyla birçok çalışma yapılmış ve yapılmaya devam edilmektedir (İnce ve Koçak, s.739; Shade ve Singh, 2016, s.2-3).

Yapılan araştırmalarda gençlerin sosyal medya kullanımlarının genellikle arkadaş edinme, video ve fotoğraf paylaşma gibi aktivitelerden oluştuğu belirtilmektedir. Gençler arasında özellikle belli gruplara dahil olmak amaciyla sosyal medya araçları sıklıkla kullanılmakta, bireylerin sosyal medya araçları üzerinden kimliklerini yansıtma imkanı bulunmaktadır. Sosyal ağlar ile bilgiye ulaşım kolay ve hızlı bir şekilde gerçekleşiyor olmakla beraber günümüzde gençlerin nitelikli bilgiye ulaşma durumları oldukça sinırlıdır (Yıldız, 2012, s.541; Yegen, 2013,s.121; Papathanassoupoulos, 2015, s.12). Sosyal medya kullanım amaçları arasında akademik bilgiye ulaşmak yerine arkadaşlık ilişkileri kurmanın daha ön planda olduğu birçok çalışmada ifade edilmektedir (Yıldız ve Demir, 2016, s.20). $\mathrm{Bu}$ durum gençler arasında sosyal medyanın işlevsel olarak kullanılmadı̆̆ının temel bir göstergesi olabilir. Sosyal medyanın gençler tarafından işlevsel olarak kullanılmaması akademik düzeyde öğrencilere önemli bir katkı sağlamayacaktır. Bu da gençlerin sosyal medya ağlarında gereksiz zaman harcamalarına ve ders başarılarının düşmesine neden olabilir (Gönenli ve Hürmeriç, 2012, s.213-214). Sosyal paylaşım sitelerinin yükseköğretimde akademik başarı ve öğrenme performansını artırmaya yönelik olumlu bir etkisinin olabileceği ancak bu kullanım sürecinin etkili ve verimli olabilmesi için öğrencilere gerekli kültürün oluşturulması gerektiği dikkate alınmalıdır (Öztürk ve Akgün, 2012, s.51 $52)$.

$\mathrm{Bu}$ araştırmada öğrencilerin sosyal medyada geçirdikleri zaman, sosyal medya kullanım sıklıkları, sosyal medya kullanım amaçları gibi faktörlerin tespiti hedeflenmiştir. 


\section{ARAŞTIRMANIN PROBLEMI}

Eğitimciler, sosyal medyayı öğrencilerin mesleki eğitim ve kişisel gelişimleri için nasıl kullanabilecekleri yönünde farkındalık sağlayabilir, eğitimi destekleyici bir avantaj haline getirilebilir ve bu etkileşimin sağlanmasında danışmanlık verebilirler. Bu bilgilerden hareketle, sağlık hizmetleri alanında eğitim gören öğrencilerin internet kullanımının önemli bir parçası olan sosyal medyayı kullanma özellikleri ve sosyal medyaya yönelik tutumlarının belirlenmesi konulu bu çalışmanın, eğitim-öğretim ortamlarında bilişim teknolojilerinden yararlanmaya yönelik daha detaylı çalışmalar yapılması konusunda veri tabanına önemli katkılar sunacağına inanılmaktadır. Bu doğrultuda çalışmada iki araştırma problemi sorusu yer almaktadır:

1. Öğrencilerin sosyal medyayı kullanım özellikleri (kullanma sıklı̆̆ı, kullanılan sosyal medya hesabı, kullanma amaçları) nelerdir?

2. Öğrencilerin sosyal medyaya yönelik tutumları nasıldır?

\section{YÖNTEM}

\section{Araştırmanın Tipi}

Araştırmada betimsel tarama modeli kullanılmıştır.

\section{Evren ve Örneklem}

Araştırmanın evrenini bir devlet üniversitesinin Sağl1k Hizmetleri Bölümlerinde öğrenim gören ögrenciler oluşturmaktadır. Çalışmaya katılmaya istekli 342 katılımcıdan yüz yüze görüşme tekniğiyle veriler toplanmıştır. Verilerin toplanmasında kolayda örneklem yöntemi seçilmiştir.

\section{Veri Toplama Aracı}

Araştırmanın verileri literatürden yararlanarak (Yıldız ve Demir, 2016; Bedir, 2016) oluşturulan ve toplam iki bölümden oluşan soru formu ve Sosyal Medyaya Yönelik Tutum Ölçeği ile elde edilmiştir. Uygulanan soru formunun ilk bölümünde, öğrencilerin demografik özellikleri (yaş, cinsiyet, okuduğu sınıf, bölüm), ikinci bölümünde ise öğrencilerin internet kullanım sıklıkları ile hangi sosyal medya araçlarını kullandıkları ve kullanım amaçlarının ne olduğu gibi sosyal medya kullanım özelliklerini belirlemeye yönelik kapalı uçlu sorular yer almaktadır. Öğrencilerin sosyal medyaya karşı tutumları ise ülkemizde geçerlik ve güvenirlik çalışması yapılmış Sosyal Medyaya Tutum Ölçeği ile değerlendirilmiştir. Ölçek Bedir'in (2016) tez çalışmasından alınmıştır. Sosyal Medyaya Tutum Ölçeği 5 dereceli Likert tipi bir ölçek olup 11 maddeden alınan toplam puan katılımcının sosyal medyaya yönelik tutum puanını yansıtmaktadır. Ölçeğin değerlendirilmesinde yüksek puan sosyal medyaya olumlu tutumu ifade etmektedir.

\section{Veri Analizi}

Araştırma verilerinin istatistiksel analizi için SPSS 21.0 istatistik programı kullanılmıştır ve istatistiksel sonuçlar \%5 güven aralığında değerlendirilmiştir. Elde edilen verilerin değerlendirilmesinde tanımlayıcı istatistikler ve ortalama alınmıştır.

\section{Etik Yönü}

$\mathrm{Bu}$ araştırma için Cumhuriyet Üniversitesi Sağl1k Hizmetleri Meslek Yüksekokulu Müdürlüğünden Sayı:991 Tarih: 06.10.2017 kurum izni alınmıştır. 


\section{BULGULAR}

Araştırmanın bu bölümünde elde edilen bulgulara yer verilmiştir.

Tablo 1: Öğrencilerin Bazı Özelliklerinin Dağılımı (n:342)

\begin{tabular}{lll}
\hline Özellikler & Sayı & \% \\
\hline Cinsiyet & & \\
Kadın & 120 & 36.8 \\
Erkek & 222 & 63.2 \\
Yass & & \\
$\mathbf{1 8 - 2 0}$ & 218 & 63.7 \\
$\mathbf{2 1}$ ve üstï & 124 & 36.3 \\
Sinıf & & \\
1.sınıf & 150 & 43.6 \\
2.sınıf & 192 & 56.4 \\
\hline
\end{tabular}

Çalışmaya katılan öğrencilerin \%36.8'i kadın, \%63.2'si erkek olup örneklem grubunun büyük çoğunluğu (\%95.9) 18-23 yaş arasındandır.

Tablo 2: Öğrencilerin Sosyal Medya Kullanım Özelliklerinin Dağılımı (n:326)

\begin{tabular}{|c|c|c|}
\hline Sosyal medya hesabı & Sayı & Yüzde \\
\hline Var & 326 & 94.5 \\
\hline Yok & 16 & 5.5 \\
\hline \multicolumn{3}{|c|}{ İnternette ortalama geçirdiği süre (saat/gün) } \\
\hline 1 saatten az & 11 & 3.3 \\
\hline $1-3$ saat & 176 & 54.0 \\
\hline 4-6 saat & 115 & 35.3 \\
\hline 6 saat ve üzeri & 24 & 7.4 \\
\hline \multicolumn{3}{|c|}{ Sosyal medyada geçirdiği süre (saat/gün) } \\
\hline 1 saatten az & 24 & 7.4 \\
\hline $1-3$ saat & 170 & 52.1 \\
\hline 4-6 saat & 107 & 32.8 \\
\hline 6 saat ve üzeri & 25 & 7.7 \\
\hline \multicolumn{3}{|c|}{ Sosyal medyayı kullanma sıklı̆̆ı } \\
\hline Her gün bir & 18 & 5.5 \\
\hline Her gün birden fazla & 262 & 80.4 \\
\hline Haftada bir & 14 & 4.3 \\
\hline Haftada birden fazla & 23 & 7.1 \\
\hline Ayda birkaç defa & 9 & 2.8 \\
\hline \multicolumn{3}{|c|}{ Sosyal medya sitelerini kullanmaya başlama Süresi (yıl) } \\
\hline 1 yildan az & 26 & 7.9 \\
\hline $1-2$ y1l & 180 & 55.2 \\
\hline 3-4 y1l & 99 & 30.4 \\
\hline 4 yildan fazla & 21 & 6.5 \\
\hline \multicolumn{3}{|c|}{ Sosyal medya sitelerine girdiği arac } \\
\hline Bilgisayar & 48 & 14.7 \\
\hline Cep telefonu & 252 & 77.3 \\
\hline Tablet (iPad, Nexus vb.) & 26 & 8.0 \\
\hline \multicolumn{3}{|c|}{ En çok kullandığı sosyal medya hesabı } \\
\hline Facebook & 202 & 62.0 \\
\hline İnstagram & 63 & 19.3 \\
\hline Youtube & 48 & 14.7 \\
\hline Diğer (Linkedin......) & 13 & 4.0 \\
\hline
\end{tabular}


Öğrencilerin sosyal medya kullanımlarına ilişkin özellikleri incelendiğinde; öğrencilerin \%94.5'i sosyal medya hesabının olduğunu, sadece \%5.5'i sosyal medya hesabının olmadığını ifade etmiştir. Öğrencilerin tümü her gün sosyal medya ortamına girdiğini ve \%92.7'si günde bir saatten fazla süre sosyal medyayı kullandıklarını belirtmiştir. Öğrencilerin \%80.4'ünün sosyal medya kullanma sıklı̆̆ her gün birden fazla sayıda iken, \%92.1'inin sosyal medya sitelerini kullanmaya başlama zamanının bir y1l ve üzerinde olduğu belirlenmiştir. Ayrıca öğrencilerin \%77.3'ü cep telefonu, \%14'ü ise bilgisayarla sosyal medya sitelerine girdiğini ve sirasıyla facebook (\%62), instagram (\%19.3), twitter (\%14.7), youtube'u (\%4) kullandıklarını ifade etmişlerdir.

Tablo 3: Öğrencilerin Sosyal Medyayı Kullanm.a Amaçlarının Dağılımı (n:326)

\begin{tabular}{lll}
\hline Sosyal Medya Sitelerini Kullanma Amacı & Sayı & Yüzde \\
\hline Fotoğraf-video paylaşmak & 106 & 32.5 \\
Sohbet etmek & 57 & 17.5 \\
Gündemi takip etmek & 54 & 16.6 \\
Derslerime katkı sağlamak & 32 & 9.8 \\
İnteraktif oyunlar & 25 & 7.7 \\
Arkadaş/akrabalarımı bulmak & 19 & 5.8 \\
Dil geliştirmek & 19 & 5.8 \\
Yeni arkadaşlar edinmek & 14 & 3.8
\end{tabular}

Öğrencilerin sırasıyla en çok fotoğraf-video paylaşmak (\%32.5), sohbet etmek (\%17.5), gündemi takip etmek (\%16.6), derslerine katk1 sağlamak (\%9.8), interaktif oyunlar oynamak (\%7.7) ve dil geliştirmek (\%5.8) gibi nedenlerle sosyal medyayı kullandıkları saptanmıştır.

Örneklem grubunu oluşturan öğrencilerin Sosyal Medya Tutum Ölçeğinden aldıkları puan ortalaması $=40.14 \pm 12.97$ olarak bulunmuştur.

\section{TARTIŞMA VE SONUÇ}

Çalışma, öğrencilerin zamanlarının büyük bir kısmını sosyal medya ağlarında geçirdikleri ve sosyal medya kullanımının gençlerin günlük yaşam aktivitelerinin önemli bir bölümü haline geldiği belirlenmiştir. Ayrıca öğrencilerin sosyal medyayı en çok sosyal paylaşım amaçlı aktiviteler (fotoğrafvideo paylaşımı, sohbet etme) için kullandıkları, çok az öğrencinin eğitimlerine katkı amacıyla bu ağlardan yararlandıkları ve öğrencilerin sosyal medyaya karşı olumlu tutum içinde oldukları saptanmıştır. Çalışmada öğrencilerin zamanlarının büyük bir kısmını geçirdikleri sosyal medyayı eğitimleri için etkili, yeterli ve bilinçli bir şekilde kullanamadıkları sonucuna ulaşılmıştır. Çalışmamızla benzer şekilde Bedir (2016) araştırmasında sosyal medya kullanımının gençler tarafından sosyalleşme aracı olarak sıklıkla tercih edildiğini belirtmiştir. Sosyal medya araçlarının gençler tarafından en yaygın kullanım şekli fotoğraf ve video paylaşımıdır. Öğrenciler sosyal medyayı sıklıkla günlük hayatarına ve ilgi alanlarına yönelik fotoğraf ve videolar paylaşarak sosyal ortamlarda aktif olmaya çalışmkatadırlar.

İnternet üzerinden etkileşimin bir sonucu olan sosyal ağlar bireylere özgürlük, özerklik, içerik yaratabilme serbestliği sağlamaktadır (Akçay, 2011). Araştırmada öğrencilerin sosyal medya ağlarından facebook, instagram gibi içeriğini kendilerinin oluşturduğu platformları daha etkin kullandıkları sonucuna ulaşılmıştır. Çalışmamızla benzer şekilde diğer çalışmalarda da sosyal medya kullanımında ilk sırada facebook ve twitter gelmektedir (Akyazı ve Ünal, 2013; Tektaş, 2014).

Öğrenciler arasında en yaygın medyaya girdikleri cihaz ise cep telefonlarıdır. Cep telefonlarının gençlerin sürekli olarak yanında olması, sosyal medya kanalları üzerinden sürekli aktif olarak etkileşim kurabilmelerini sağlamaktadır (Onat, 2010; Görenli ve Hürmeriç, 2012). Öğrenciler arasında bu durum gündelik yaşamın bir parçası olarak görülmektedir. Sosyal medyanın bir sosyalleşme aracı olarak kullanılması ve akademik anlamda önemli katkılar yaratmaması, sosyal medya araçlarının eğitime olan etkisini sorgulatmaktadır. 
$\mathrm{Bu}$ çalışmada öğrencilerin sosyal medya tutumları olumlu bulunmuştur. Atalay'ın (2014) yaptığı çalışmada da öğrencilerin sosyal medya tutumları ve kullanım sıklıkları yüksek olarak bulunmuştur.

Sonuç olarak teknoloji çağının gereklilikleri olarak internet kullanım oranları tüm yaş gruplarında giderek artmaktadır. Çalışmadan elde edilen veriler eşliğinde, internet kullanımının büyük çoğunluğunu sosyal medya araçları oluşturmaktadır. Öğrencilerin sosyal medya ağlarını eğitimlerine katkı sağlayacak, kişisel gelişimlerini destekleyecek, akademik başarılarını arttıracak, eğitsel içeriklerle desteklenmesi için uygun programlar geliştirilmelidir. Öğrencilerin, eğitim aldıkları alanla entegrasyonu sağlanarak sosyal ağları daha verimli kullanmalarını sağlayacak ders içerikleri müfredat programlarına eklenmelidir.

Bilgilendirme / Acknowledgement: Bu çalışma 1. Uluslararası Sosyal, Beşeri ve Eğitim bilimleri Kongresi, 22-23 Aralık 2017, İstanbul'da "Sağlık Hizmetleri Meslek Yüksekokulu Öğrencilerinin Sosyal Medya Kullanım Özellikleri ve Tutumlarının İncelenmesi” başlıklı sözlü bildiri olarak sunulmuştur.

\section{KAYNAKÇA}

Akar, E. (2010). Sosyal medya pazarlamast: Sosyal webde pazarlama stratejileri. Ankara: Efil Yayınevi.

Akçay, H., (2011). Kullanımlar ve doyumlar yaklaşımı bağlamında sosyal medya kullanımı: Gümüşhane Üniversitesi üzerine bir araştırma. İletişim Kuram ve Araştırma Dergisi, 33: 137-161.

Akyazı, E., \& Ünal, A. T. (2013). İletişim fakültesi öğrencilerinin amaç, benimseme, yalnızlık düzeyi ilişkisi bağlamında sosyal ağları kullanımı. Global Media Journal Turkish Edition, 6(3): 1-24.

Atalay, R. (2014). Lise öğrencilerinin sosyal medyaya ilişkin tutumlart ile algıladıkları sosyal destek düzeyleri arasındaki ilişki. Yayınlanmış yüksek lisans tezi. Marmara Üniversitesi Eğitim Bilimleri Enstitüsü, İstanbul.

Barutçu, S., \& Tomaş, M. (2013). Sürdürülebilir sosyal medya pazarlaması ve sosyal medya pazarlaması etkinliğinin ölçümü. İnternet Uygulamaları ve Yönetimi Dergisi, 1: 5-24.

Bedir, A. (2016). Sosyal medya kullanımının üniversite öğrencilerinin akademik başarılarına ve tutumlarına etkisi. Yüksek lisans tezi. Atatürk Üniversitesi Eğitim Bilimleri Enstitüsü, Erzurum.

Çağlar, B. (2014). Yerel kimliğin sosyal ağlarda yeniden inşaası: Hemşeri derneklerinin Facebook sayfalarının incelenmesi. (Sayımer, İ., ed.). Yeni Medya Araştırmaları Kavramlar, Uygulamalar, Tartışmalar içinde, 488, Konya:Literatürk.

Çildan, C., Ertemiz, M., Tumuçin, H. K., Küçük, E., \& Albayrak, D. (2012). Sosyal medyanın politik katılım ve hareketlerdeki rolü. Akademik Bilişim, 1-3.

Eren, V., \& Aydın, A. (2014). Sosyal medyanın kamuoyu oluşturmadaki rolü ve muhtemel riskler. KMÜ Sosyal ve Ekonomik Araştırmalar Dergisi, 16(Özel Sayı I): 197-205.

Fuchs, C. (2017). Social media: A critical introduction. California: Sage.

Gönenli, G., \& Hürmeriç, P. (2012). Sosyal medya: bir alan çalışması olarak Facebook kullanımı. Sosyal Medya/Akademi içinde, 213-242.

Hazar, M. (2011). Sosyal medya bağımlılı̆̆1-bir alan çalışması. Iletişsim Kuram ve Araştırma Dergisi, 32(1): 151-76. 
İnce, M., \& Koçak, M. C. (2017). Üniversite öğrencilerinin sosyal medya kullanım alışkanlıkları: Necmettin Erbakan Üniversitesi örneği. Karabük Üniversitesi Sosyal Bilimler Enstitüsü Dergisi, 7(2): 736-749.

Kahraman, M., (2010). Sosyal medya 101. 1. Bask1. İstanbul: Mediacat Yayınlar1.

Karaca, Mehmet (2007). Sosyolojik bir olgu olarak internet gençliği: Elazı̆̆ örneği. Yayınlanmamış doktora tezi, Frrat Üniversitesi, Elazığ.

Kaplan, A. M., \& Haenlein, M. (2010). Users of the world, unite! The challenges and opportunities of Social Media. Business horizons, 53(1): 59-68.

Kim, W., Jeong, O. R. \& Lee, S. W. (2010). On social Web sites. Information Systems, 35(2): 215236.

Kirtiş, K. A., Karahan, F. (2011). To be or not to be in social media arena as the most cost-efficient marketing strategy after the global recession. Procedia Social and Behavioral Sciences, 24: 260268.

Kuyucu, M., (2013). Yeni iletişim teknolojileri ve yeni medya: Yeni iletişim aracı olarak sosyal medya ve sosyal ağlar üzerine bir güncelleme. İstanbul: Zinde Yayıncılık.

Lin, L. Y., Sidani, J. E., Shensa, A., Radovic, A., Miller, E., Colditz, J. B. \& Primack, B. A. (2016). Association between social media use and depression among US young adults. Depression and anxiety, 33(4): 323-331.

Onat, F. (2010). Bir halkla ilişkiler uygulama alanı olarak sosyal medya kullanımı: Sivil toplum örgütleri üzerine bir inceleme. Gazi Üniversitesi İletişim Fakültesi Illetişim Kuram ve Araştırma Dergisi, 31: 103-122.

Öztürk, M. F., \& Talas, M. (2015). Sosyal medya ve eğitim etkileşimi. Zeitschrift für die Welt der Türken/Journal of World of Turks, 7(1): 101-120.

Öztürk, M., \& Akgün, Ö. E. (2012). Üniversite öğrencilerinin sosyal paylaşım sitelerini kullanma amaçları ve bu sitelerin eğitimlerinde kullanılması ile ilgili görüşleri. Sakarya University Journal of Education, 2(3): 49-67.

Pangrazio, L., \& Selwyn, N. (2018). "It's not like 1t's life or death or whatever": Young people's understandings of social media data. Social Media+ Society, 4(3):1-9.

Papathanassopoulos, S. (2015). Privacy 2.0. Social Media \& Society, 1-2.

Patel, D. (2017). Social media marketing: Social media marketing fundamentals. VDS Developers.

Pempek, T. A., Yermolayeva, Y. A., Calvert, S. L. (2009). College students' social networking experiences on Facebook. Journal of Applied Developmental Psychology, 30: 227-238.

Shade, L. R., \& Singh, R. (2016). "Honestly, we're not spying on kinds": School surveillance of young people's social media. Social Media \& Society, 2(4): 1-12.

Solmaz, B., Tekin, G., Herzem, Z., \& Demir, M. (2013). İnternet ve sosyal medya kullanımı üzerine bir uygulama. Selçuk Üniversitesi Illetişim Fakültesi Akademik Dergisi, 7(4): 23-32.

Tektaş, N. (2014). Üniversite öğrencilerinin sosyal ağları kullanımlarına yönelik bir araştırma. Tarih Okulu Dergisi, 2014(XVII). 
Vural, Z., \& Bat, M. (2010). Yeni bir iletişim ortamı olarak sosyal medya: Ege Üniversitesi iletişim fakültesine yönelik bir araştırma. Journal of Yasar University, 5(20): 3348-3382.

Yağmurlu, A. (2011). Kamu yönetiminde halkla ilişkiler ve sosyal medya. Selçuk Üniversitesi İletişim Fakültesi Akademik Dergisi, 7(1): 5-15.

Yegen, C. (2013). Demokratik ve yeni bir kamusal alan olarak sosyal medya. Anemon Muş Alparslan Üniversitesi Sosyal Bilimler Dergisi, 1(2): 119-135.

Yıldız, A. K. (2012). Sosyal paylaşım sitelerinin dijital yerlilerin bilgi edinme ve mahremiyet anlayışına etkisi. Bilgi Dünyası, 13(2): 529-542.

Yıldız, A., ve Demir, F.M. (2016). Üniversite öğrencilerinin internet ve sosyal medya kullanım amaçlarının belirlenmesine yönelik bir araştırma: Muğla Sitk1 Koçman Üniversitesi örneği. Sosyal ve Beşeri Bilimler Araştırmaları Dergisi, 1 (37 Girişimcilik Özel Sayısı), 18-36.

We are social. (2018). Global Digital Report 2018. 14 Mart 2019 tarihinde https://digitalreport.wearesocial.com/ adresinden erişildi. 